\title{
Wastewater Treatment from Galvanization Industry with Zinc recovery
}

\author{
Svetlana Zueva ${ }^{1,2, *}$, Francesco Ferella ${ }^{1}$, Nicolò M. Ippolito ${ }^{1}$, Elena Ruduka $^{2}$, and Ida De Michelis ${ }^{1}$ \\ ${ }^{1}$ Department of Industrial and Information Engineering and Economics, University of L'Aquila, 67100 L'Aquila, Italy \\ ${ }^{2}$ Department of Chemical Engineering, Voronezh State University of Engineering, 394036 Voronezh, Russia
}

\begin{abstract}
The resistance of steel to corrosion is obtained with a number of industrial processes based on Zn galvanization. However, all these methods bear a relatively high price tag due to the cost of Zinc plates and electrolytes as well as the formation of hazardous wastewaters containing metals and acids. Wastewaters from Zn galvanization may be grouped into two main types: Mix of Rinse Water (MRW) and Spent Pickling Solutions (SPS). Ordinarily, these waters are mixed and sent for treatment by precipitation. As a result large volumes of galvanic sludge is formed, containing iron, calcium, sulphates and a relatively small quantity of zinc $(<20 \%)$, which makes Zn recovery not profitable. The experimental results presented in this article show that it is possible to use as a coagulant to treat the process wastewaters the spent pickling solution (SPS) from the process, kept separated and added with sodium hydroxide. This results in obtaining precipitates with $\mathrm{Zn}$ contents higher than $40 \%$, which brings the further advantage of making $\mathrm{Zn}$ recovery profitable.
\end{abstract}

\section{Introduction}

Galvanization with Zinc is a commonly used method to increase the corrosion resistance of steel ( $\mathrm{Zn}$ galvanizing) [1,2]. The process entails the following steps: 1) degreasing, 2) pickling with hydrochloric acid in order to remove iron oxides such as rust or scale, 3) rinsing with water and fluxing so as to chemically activate the surface and enhance the reaction with zinc. [3].

The effluent from this process is considered a special-hazardous-waste because of the high concentration of metals and acids in the waste water caused by the reduced length of the pickling stage which ordinarily is carried out in the industry in order to contain treatment time within economically viable limits. As a result, spent pickling solutions (SPSs) are hazardous and wasteful. Consequently, regeneration of spent pickling solutions is highly desirable for both environmental protection and the economic viability of industrial processes.

Worldwide, recovery of $\mathrm{HCl}$ with the pyro metallurgical method is obtained on an industrial scale in about 80 plants in the world [4]. Disadvantages are as follows: 1) environment unfriendliness, 2) high energyconsumption and, 3) the impossibility to process solutions containing more than $0.5 \mathrm{~g} / \mathrm{L}^{3}$ of zinc(II). Some membrane techniques were proposed to recover $\mathrm{HCl}$, among them diffusion dialysis [5,6] and membrane distillation [7,8]. Another way to recycle the acid is through electro dialysis of spent pickling solutions [9].
All these methods, however, are affected by the formation of undesired by-products (e.g.: chlorine gas).

Various methods of SPS regeneration are currently in use in the industry, depending on the concentration of the chemicals present in the water. With most of them only hydrochloric acid is recovered, leaving behind zinc and iron which form a concentrated sludge that is disposed without further treatment, notwithstanding the fact that Zinc is an expensive material. Hence the search for methods to recover it also from these types of processes. As it turns out, at the present state of the art Zinc recovery is cost-effective if its content in solid waste is higher than $40 \% \mathrm{w} / \mathrm{w}$.

Separation of Iron and Zinc from SPSs can be obtained through chemical processes such as ion exchange, solvent extraction and chemical precipitation.

Ion exchange needs large volumes of resin and consequently high investment costs. Furthermore, resin regeneration would produce large volumes of diluted zinc solutions, thus requiring further treatment and disposal. Separation of $\mathrm{Zn}$ from SPSs may also be effected through solvent extraction $[11,12]$, membranebased solvent extraction [13] and solvent extraction followed by precipitation-stripping [14-16]. Solvent extraction methods make it possible to separate $\mathrm{FeCl}_{2}$ and $\mathrm{ZnCl}_{2}$ from $\mathrm{HCl}$ but as a rule they have a high cost and result in solvent loss to aqueous effluents.

A very common and simple treatment applied to galvanic wastewaters is chemical precipitation with lime. In order to reduce the volume and water content of the precipitate formed at the last stage of sedimentation,

\footnotetext{
* Corresponding author: svetlana.zueva@graduate.univaq.it
} 
inorganic coagulants (for example, iron chloride) or polyelectrolytes are added to the wastewater.

Zinc can be recovered in insoluble forms as hydroxides by using several alkaline reagents, like $\mathrm{CaO}$ or $\mathrm{Ca}(\mathrm{OH})_{2}, \mathrm{Mg}(\mathrm{OH})_{2}, \mathrm{NaOH}$, and $\mathrm{NH}_{4} \mathrm{OH}[17,18]$.

Coagulation and flocculation followed by sedimentation and filtration also employed to remove heavy metal from wastewaters. Coagulation is the destabilization of colloids by neutralizing the forces that keep them apart. Many coagulants are widely used in the conventional wastewater treatment processes such as aluminium, ferrous sulphate and ferric chloride, resulting in the effective removal of wastewater particulates and impurities by charge neutralization of particles and by enmeshment of the impurities on the formed amorphous metal hydroxide precipitates.

Disadvantage of the reagent method is the formation of large amounts of sludge containing toxic compounds of heavy metals. The final disposal of such sludge requires chemical treatments and appropriate landfills.

This article describes a research which led to the definition of a method, which makes Zinc recovery from galvanization wastewater possible and financially viable by utilizing as a coagulant in the process part of the waste itself.

\section{Materials and Methods}

Experiments were carried out on 2 no. samples: Spent Pickling Solution (SPS), and three samples of Mix Rinse Water (MRW).

Hydrated lime (calcium hydroxide) $10 \%$ (w/v), sodium hydroxide $40 \%$ (w/v), $\mathrm{FeCl}_{3}(40 \% \mathrm{v} / \mathrm{v})$ were used for the precipitation tests.

The study consisted of four sets of experiments. As an alternative to lime, in order to increase the mass content in the resulting zinc precipitate, the deposition process was carried out with sodium hydroxide and SPS instead of iron chloride.

In order to evaluate the content of $\mathrm{Zn}, \mathrm{Fe}$, and $\mathrm{Ca}$ in the precipitate a quantitative analysis was carried out after the acid attack. The acid attack was performed in a $25 \mathrm{~mL}$ closed flask as follows: around $0.5 \mathrm{~g}$ of initial materials was dissolved with $1: 3$ of nitric and hydrochloric acid at $90{ }^{\circ} \mathrm{C}$.

An X-ray fluorescence XRF spectrophotometer (Spectro XEPOS 2000) and a fast sequential atomic absorption spectrometer (Varian AA240FS) were used to perform the chemical analyses of wastewater and wastewater precipitate.

Chlorides and COD were measured with Dr. Lange's kit, cuvette-test LCK 153 and LCK 114A.

Samples were analysed for total suspended solids (TSS) using a modified version of the Standard Method 2540 for solids determinations in the water and wastewater industry.

During the precipitation stage, the reagents were gradually added under constant stirring until reaching $\mathrm{pH}=9.5-10$. The mixture was stirred further for $2 \mathrm{~h}$ in order to ensure precipitation equilibrium. After what different coagulant $\left(\mathrm{FeCl}_{3}\right.$ or SPS) were added and stirred at approximately $100 \mathrm{rpm}$ for 1 minute. Then the stirring speed was reduced to $50 \mathrm{rpm}$ and continued mixing for 15 to 20 minutes.

The final $\mathrm{pH}$ was then was measured and the precipitate was separated by vacuum filtration, washed three times with demineralized water and then dried at $105{ }^{\circ} \mathrm{C}$ overnight. In order to evaluate the content of $\mathrm{Zn}$, $\mathrm{Fe}$ and $\mathrm{Ca}$ in the precipitate a quantitative analysis was carried out after acid attack. The acid attack was performed in a $25 \mathrm{~mL}$ closed flask as follows: around 0.5 $\mathrm{g}$ of initial materials was dissolved with 1:3 of nitric and hydrochloric acid at $90^{\circ} \mathrm{C}$.

According to the European and national standards the permissible content of $\mathrm{Zn}$ is $2 \mathrm{mg} / \mathrm{L}$ and $\mathrm{Fe} 10 \mathrm{mg} / \mathrm{L}$.

\section{Results and Discussion}

Table 1 shows the composition of wastewater after different treatment strategies.

Table 1. Wastewater parameters before and after treatment.

\begin{tabular}{|c|c|c|c|c|c|}
\hline & $\mathrm{pH}$ & $\begin{array}{c}\mathrm{Zn} \\
\mathrm{mg} / \mathrm{L}\end{array}$ & $\begin{array}{c}\mathrm{Fe} \\
\mathrm{mg} / \mathrm{L}\end{array}$ & $\begin{array}{c}\mathrm{Cl} \\
\mathrm{mg} / \mathrm{L}\end{array}$ & $\begin{array}{c}\mathrm{SO}_{4} \\
\mathrm{mg} / \mathrm{L}\end{array}$ \\
\hline $\mathrm{WW}$ & 6.2 & 88.87 & 3.48 & 1010 & 499 \\
\hline $\mathrm{CA}$ & 0.4 & 6654 & 2992 & 321000 & 169 \\
\hline $\mathrm{Lime}+\mathrm{FeCl}_{3}$ & 9.2 & 0.59 & 0.04 & 854 & 250 \\
\hline $\mathrm{NaOH}+\mathrm{FeCl}_{3}$ & 9.6 & 0.88 & 0.08 & 854 & 280 \\
\hline $\mathrm{Lime}+\mathrm{SPS}$ & 9.4 & 0.95 & 0.05 & 1120 & 190 \\
\hline $\mathrm{NaOH}+\mathrm{SPS}$ & 9.5 & 0.43 & 0.03 & 1120 & 270 \\
\hline
\end{tabular}

As it can be seen from the results of experiments (Fig. 1), Zn completely precipitated within $2 \mathrm{~h}$ after reaching desired $\mathrm{pH}=9.5$ (treatment $n .1$ ). In the case of precipitation with $\mathrm{NaOH}$ and SPS, 1 hour was enough to reach maximum zinc removal.

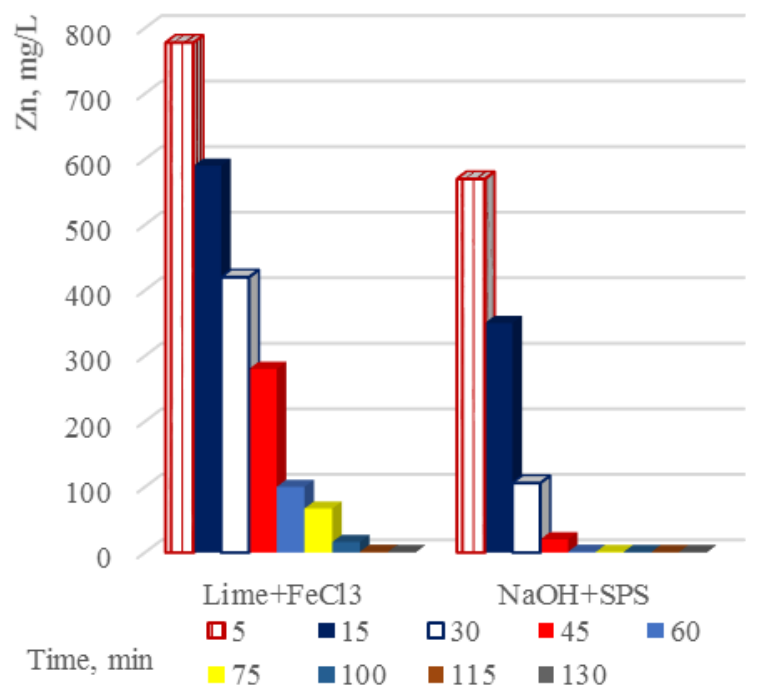

Fig. 1. Concentrations of $\mathrm{Zn}$ as a function of reaction time after reaching $\mathrm{pH} 9.5$.

Results of experiments demonstrated that the concentration of $\mathrm{Zn}$ was significantly lower in the wastewater sample treated with $\mathrm{NaOH}$ and SPS, compared to lime and $\mathrm{FeCl}_{3}$. From other hand, 
replacement of lime and iron chloride with sodium hydroxide and SPS did increase the zinc content in the sludge from $33.3 \%$ to $46.0 \%$ (Fig. 2).

Furthermore, spent pickling solution (SPS) did demonstrate a good coagulating effect. This can be explained by fact that in an acidic chloride solution such an SPS, Fe (II), Fe(III) and $\mathrm{Zn}$ (II) exist as a series of chloride complexes: $\mathrm{ZnCl}_{2}, \mathrm{Fe}^{2+},[\mathrm{FeCl}]^{+},[\mathrm{FeCl}]^{2+}$, $\left[\mathrm{FeCl}_{2}\right]^{+}$, and $\mathrm{FeCl}_{3}$ [3]. In fact, the filtration rate of the samples after the addition of $\mathrm{FeCl}_{3}$ and SPS was the same.

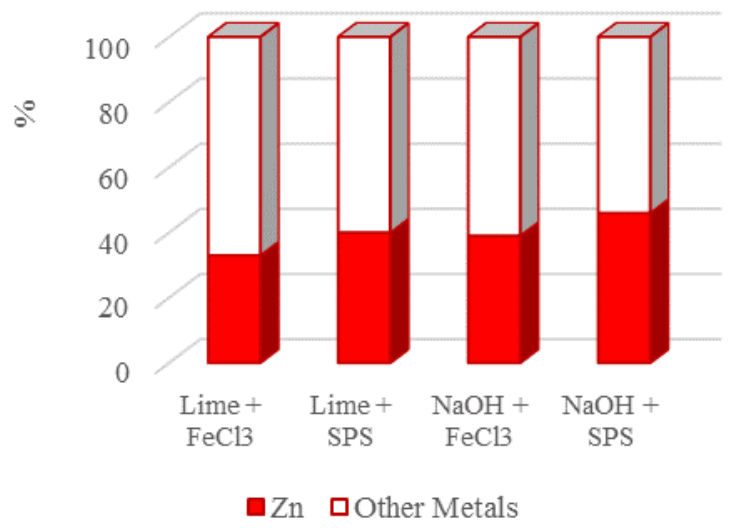

Fig. 2. Comparison of $\mathrm{Zn}$ content in the precipitate after precipitation with sodium hydroxide, lime, and ferric chloride and SPS as coagulants.

The flowchart of the process is shown in the Fig. 3 . The process consists of a precipitation step with sodium hydroxide for $1 \mathrm{~h}$, followed by coagulation with SPS and further filtration to separate the precipitate from the liquid. The solid can be dried and then sold for $\mathrm{Zn}$ recovery, while the treated water could be sent to $\mathrm{Cl}$ recovery.

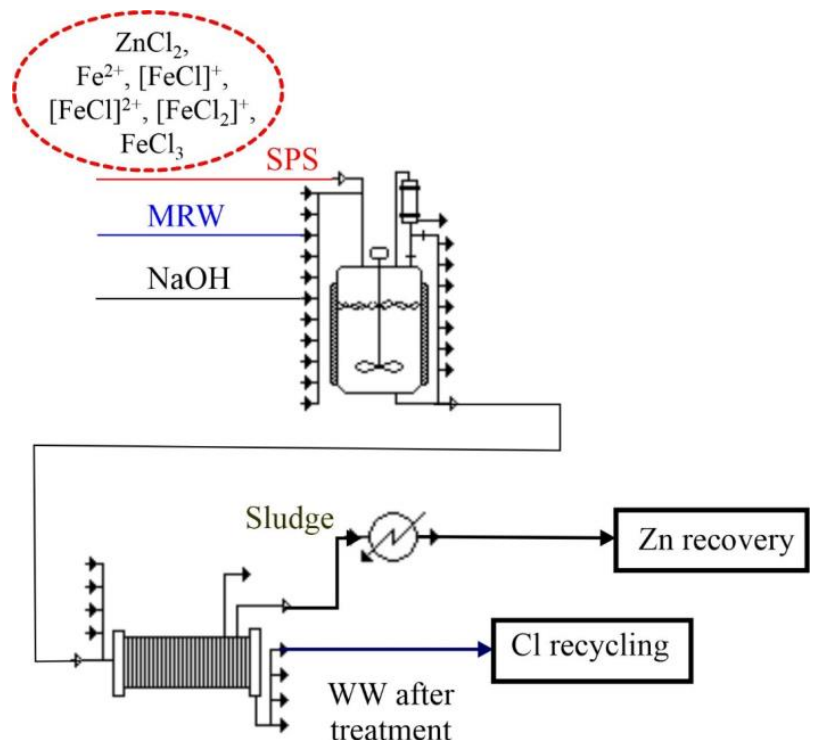

Fig. 3. Flow-chart of the process.

According to the mass balance, SPS consumption to treat $10 \mathrm{~m}^{3} / \mathrm{h}$ of MRW, was $20 \mathrm{~L} / \mathrm{h}$. Taking into account that up to $600 \mathrm{~L}$ of SPS per day is formed at the enterprise $(\max 25 \mathrm{~L} / \mathrm{h})$, the proposed purification scheme allows the entire SPS to be processed as a coagulant.

In conclusion, replacing calcium hydroxide with iron hydroxide will reduce the sediment volume by a quarter and increase the zinc content by 1.4 times. In 2019, the company sent 374.8 tons of sludge to an authorized disposal site and paid 140 thousand euros for processing. The increase in zinc content in the sludge will change the nature of the sludge from a hazardous waste class (F019) into a by-product suitable for subsequent zinc recovery, thus eliminating the aforementioned disposal costs. As a result, annual savings of about 140 thousand euros can be obtained by replacing the previously used coagulant $\left(\mathrm{FeCl}_{3}\right)$ with waste from the purification stage and by recycling the sludge instead of sending it for expensive disposal.

\section{Conclusions}

This research led to the following findings.

An increase of the Zinc content in sludge of almost $100 \%$ (from $33 \%$ to $46 \% \mathrm{w} / \mathrm{w}$ ) was obtained by replacing the commonly used treatment with Lime and $\mathrm{FeCl} 3$ with the introduction of $\mathrm{NaOH}$ and SPS water. This increase in $\mathrm{Zn}$ content made recovery of Zinc cost effective.

The residual concentration of $\mathrm{Zn}$ and $\mathrm{Fe}$ in the wastewater resulting from the proposed process was below the admissible legal limits.

The new treatment resulted in annual savings of about $140,000.00$ euro because the plant did not have to bear, thence forward, the cost of the legal disposal of the sludge.

The authors are very grateful to Fabiola Ferrante and Marcello Centofanti for their helpful collaboration given for the XRF and AAS analyses.

\section{References}

1. J. Pirošková, J. Trpcevská, B. Hluchánová, M. Laubertová, Acta Metall. Slovaca. 18, 34-39. (2012)

2. M.A. Bright, N.J. Deem, J. Fryatt, Light Metals. Edited by TMS (Miner. Met. Mater. Soc.). 101-109. (2007)

3. L. Pietrellia, S.Ferrob, M. Vocciantec, Chem. Eng. J. 341, 539-546. (2018)

4. M. Regel-Rosocka, A. Cieszycska, M. Wioeniewski. Pol. J. Chem. Technol. 9, 42-45. (2007)

5. Nalienaa Muthu, Faieza Abdul Aziz, Rosnah Binti Mohd Yusuf. Global Journal of Researches in Engineering. 13 (6). (2013)

6. R.M.M. Machado, M.L.F. Gameiro, J.M.A. Rodrigues, M.R.C. Ismael, T.A. Reis, J.M.R. Carvalho. Sep. Sci. Tech. 52 (8), 1333-1340. (2017)

7. M. Regel-Rosocka J. Hazard. Mater. 177, 1-3, 5769. (2010) 
8. A. Devi, A. Singhal, R. Gupta. Clean Techn. Environ. Policy. 16, 1515-1527. (2014)

9. L. Gurreri, A. Tamburini, A. Cipollina, G. Micale. Membranes. 10, 146. (2020)

10. F. Rogener, M. Sartor, A. Ban, D. Buchloh, T. Reichardt. Resour. Conserv. Recycl. 60, 72-77. (2012)

11. Y. Wang; Y. He ; S. Yin; H. Long; S. Li Hydrometallurgy. 93, 105322. (2020)

12. S. Randazzo, V. Caruso, D. Ciavardelli, G. Micale, M. Morreale. Desalination Water Treat. 157, 110117. (2019)

13. J. Laso,; V. García, E. Bringas, A.M. Urtiaga, I. Ortiz, Industrial \& Engineering Chemistry Research. 54 (12), 3218-3224. (2015)

14. S. Khyati, G. Kamalesh, S. Bina. J. Environ. Chem. Eng. 5. 5260-5269. (2017)

15. 17. J.F. Blais, Z. Djedidi, R. Ben Cheikh, R. D. Tyagi, G. Mercier. Practice Periodical of Hazardous Toxic and Radioactive Waste Management 12 (3) DOI: $\quad 10.1061 /(A S C E) 1090-025 X(2008) 12: 3(135)$ (2008)

16. T.A. Kurniawan, G.Y.S. Chan, W.H. Lo, S. Babel. Sci. Total Environ. 366 (2-3), 409-426. (2006). 